\title{
Influence of blood meal and mating in reproduction patterns of Triatoma brasiliensis females (Hemiptera: Reduviidae) under laboratory conditions
}

\author{
Natália Faria Daflon-Teixeira1', Filipe Aníbal Carvalho-Costa², Ralem Gary Chiang ${ }^{3}$, \\ Marli Maria Lima ${ }^{1 /+}$
}

'Laboratório de Eco-Epidemiologia da Doença de Chagas ²Laboratório de Sistemática e Bioquímica, Instituto Oswaldo Cruz-Fiocruz, Rio de Janeiro, RJ, Brasil ${ }^{3}$ Biology Department, Redeemer University College, Ancaster, Ontario, Canada

The influence of blood meal and mating on Triatoma brasiliensis (Neiva) female fecundity, fertility, life-span and the preoviposition period were investigated under laboratory conditions. Nourishment increased fecundity, fertility and adult lifespan, whereas mating increased fecundity, fertility and decreased the preoviposition period. Females also required more than one mating to reach their full reproductive potential. Results indicate that both nourishment and mating are important in $\mathrm{T}$. brasiliensis proliferation. Such information will help towards developing effective control strategies of this vector of Chagas disease.

Key words: Triatoma brasiliensis - triatomine - fecundity - fertility

Triatoma brasiliensis is one of the most important species vectors of Chagas disease in Brazil, found mainly in the semi arid region of the Brazilian Northeast. Its large colonies in wild and domiciliary units, coupled with its high rate of Trypanosoma cruzi infection and ability to reinvade domiciliary environments shortly after insecticide application (Dias 1995) attest to its epidemiological importance. The purpose of this study was to investigate the influence of the blood meal and mating on the T. brasiliensis female to evaluate the role of these components in the fecundity, fertility, preoviposition period and life-span. Considering that reproductive success is intimately associated with the potential for colonizing or re-colonizing new ecotopes in endemic areas, this information will help in designing effective control strategies.

T. brasiliensis used in this study were third generation insects taken from an endemic area situated in the semi arid region of the state of Ceará, Brazil, and held in the laboratory at $28.6 \pm 2.7^{\circ} \mathrm{C}$ and $77.7 \pm 10 \%$ humidity. Fifth instar nymphs from this colony were sex-screened (Espínola 1966) and male and female nymphs separated into different glass vials. They were fed fortnightly on live pigeons until the imaginal ecdysis (procedure approved by the Animal Use and Care Committee at Oswaldo Cruz Foundation, license L-0064/08).

The insects were divided into the following groups:

\section{Animals fed fortnightly on pigeon blood}

Multiple mated females - Twenty couples were placed into individual glass vials and any male that died before

Financial support: $\mathrm{CNPq}$, Fiocruz

+ Corresponding author:mmlima@ioc.fiocruz.br

Received 15 May 2009

Accepted 27 August 2009 the female was immediately replaced with live males no older than 15 days post emergence. The number of matings by a female was determined by the number of Spermatophore casings found in the glass vials (Figure).

Single mated females - Thirty-six couples were placed into individual glass vials and after copulation the male was removed. Mating was confirmed by the presence of a Spermatophore casing in the glass vial and the female remained alone until death.

Unmated females - Thirty-five unmated females were collected immediately after the last ecdysis and placed into individual glass vials.

\section{Animals receiving no food after the last ecdysis}

Multiple mated females - Fourteen recently ecdysed females were separated into individual glass vials and each one stayed with a male all the time.

Unmated females - Forty-two virgin females were separated into individual glass vials immediately after the last ecdysis.

The groups were observed daily until the death of all females. The eggs laid by the mated female groups were kept for 30 days to ascertain the number that hatched into nymphs. Statistical analysis was carried out by the Mann-Whitney and Chi-square tests; a p-value less than 0.05 was considered statistically significant.

Feeding was a powerful stimulus for egg production. Mated and unmated fed animals produced approximately 15 fold the number of eggs compared to their unfed counterparts, a difference that was highly significant $(p<0.001)$. This finding is consistent with our knowledge of hematophagous species, such as triatomines, in which the ingestion of a blood meal initiates egg production by acting through the endocrine and nervous systems (Wigglesworth 1959, 1972). However, feeding alone did not increase egg production to its 


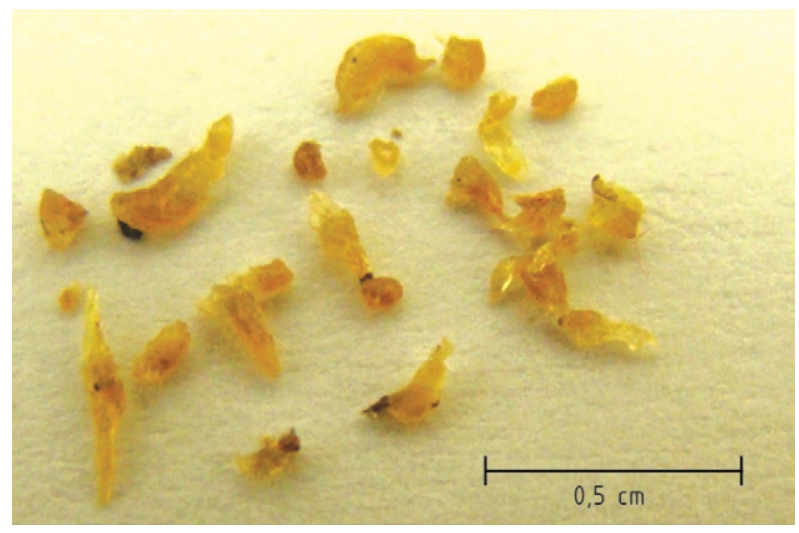

Spermatophore casings of Triatoma brasiliensis.

maximum level, as fed mated insects produced significantly more eggs than fed unmated ones. Thus mating also contributes to increased fecundity.

To investigate the influence of mating on reproduction in T. brasiliensis, we compared the mating status to the number of eggs laid (fecundity), \% fertile eggs (fertility), preoviposition period and adult life-span of fed and unfed animals. In fed animals (Table I), multiple mating was more effective than a single mating as multiple mated females produced more eggs than single mated females and demonstrated a much higher $\%$ fertility $(p<0.001)$. Interestingly, fed unmated females laid as many eggs as the fed single mated females. However, both multiple mated and single mated fed animals showed a decrease in the preoviposition period compared to unmated fed females. Life-span means ranged from 89.8-115.2 days with no difference between mated and unmated animals.

In unfed animals (Table II), the mating status had an effect similar to that seen in fed animals. The multiple mated unfed insects produced significantly more eggs than their unmated counterpart and the mean value of the preoviposition period was shorter in the mated animals. This latter comparison was not significantly different, but any significance may have been masked by the very low oviposition frequency of the unfed females. The $\%$ fertility of multiple mated unfed females was also similar to that seen for multiple mated fed females although it has been reported recently that unfed females of $T$. brasiliensis reject the majority of attempts by males (Vitta \& Lorenzo 2009). Since the males remained with the unfed females for the duration of the female's life span in our study, unfed T. brasiliensis will eventually mate given sufficient time. But without nourishment, the adult life-span of unfed animals was significantly reduced to approximately half the length for fed females.

According to several authors, egg production in triatomines is not solely dependent on ingestion of a large blood meal, for it can occur in the absence of feeding if unfed females have sufficient food stores in their digestive tract (Davey 1974, Garcia \& Azambuja 1985, Davey $\&$ Singleton 1989). Further, the source of food may be a factor in fecundity. As a result of obtaining their nutrition from a single food source, the triatomine diet may lack certain vitamins and nutrients and the origin of the blood can influence their fecundity (Valle et al. 1987, Lima et al. 1990, Garneri et al. 2000). In our laboratory, the insects obtained their food from pigeons acquired in the market. Although it is possible that a shortage of hemoglobin, vitamins or proteins in a single food source may influence egg production, the high fecundity levels of our multiple mated fed females suggest that pigeon blood alone is sufficient for the maintaining a viable population of T. brasiliensis. The results of the present study are therefore considered to represent a similar response that would be recorded from insects in their native setting.

Besides ingestion of a blood meal, mating is a stimulus for egg production that appears to enhance, but is independent of the feeding stimulus. Lima et al. (1987b)

TABLE I

Mating versus fecundity, fertility, time of oviposition (days) or life span (days) of fed females

\begin{tabular}{|c|c|c|c|c|}
\hline Fed females & $\begin{array}{l}\text { Multiple mated } \\
\text { (a) }\end{array}$ & $\begin{array}{l}\text { Single mated } \\
\text { (b) }\end{array}$ & $\begin{array}{l}\text { Unmated } \\
\text { (c) }\end{array}$ & p-value \\
\hline $\mathrm{n}$ & 20 & 36 & 35 & - \\
\hline Eggs laid ${ }^{a}$ & $53.2 \pm 52.0$ & $24.6 \pm 40.0$ & $15.6 \pm 20.4$ & $\begin{array}{c}\mathrm{a} \times \mathrm{b}(0.002) \\
\mathrm{a} \times \mathrm{c}(<0.001) \\
\mathrm{b} \times \mathrm{c}(0.590)\end{array}$ \\
\hline Fertile eggs laid ${ }^{a}$ & $38.4 \pm 42.7$ & $11.9 \pm 18.3$ & - & $\mathrm{a} \times \mathrm{b}(0.006)$ \\
\hline$\%$ fertile eggs & 72.1 & 38.9 & - & $\mathrm{ax} \mathrm{b}(<0.001)^{b}$ \\
\hline Preoviposition period $^{a}$ & $21.1 \pm 18.5$ & $23.4 \pm 8.8$ & $38.2 \pm 23.6$ & $\begin{array}{l}\mathrm{a} \times \mathrm{b}(0.022) \\
\mathrm{a} \times \mathrm{c}(0.001) \\
\mathrm{b} \times \mathrm{c}(0.015)\end{array}$ \\
\hline Adult life $\operatorname{span}^{a}$ & $115.2 \pm 51.4$ & $89.8 \pm 59.8$ & $109.5 \pm 58.0$ & $\begin{array}{l}\mathrm{a} \times \mathrm{b}(0.038) \\
\mathrm{a} \times \mathrm{c}(0.552) \\
\mathrm{b} \times \mathrm{c}(0.054)\end{array}$ \\
\hline
\end{tabular}

Mann Whitney test. $a$ : mean \pm standard deviation; $b$ : Chi-square test; $\mathrm{n}$ : number of specimens. 


\section{TABLE II}

Mating versus fecundity, fertility, time of oviposition (days) or life span (days) of starved females

\begin{tabular}{lccc}
\hline Unfed females & Multiple mated & Unmated & p-value \\
\hline $\mathrm{n}$ & 14 & 42 & - \\
Eggs laid $^{a}$ & $5.7 \pm 4.4$ & $1.1 \pm 2.8$ & $<0.001$ \\
Fertile eggs laid $^{a}$ & $3.64 \pm 3.9$ & - & - \\
$\%$ fertile eggs & 63.8 & - & - \\
Preoviposition period $^{a}$ & $23.7 \pm 7.5$ & $30.3 \pm 17.9$ & 0.645 \\
Adult life span $^{a}$ & $60.7 \pm 17.8$ & $53.5 \pm 19.3$ & 0.185 \\
\hline
\end{tabular}

Mann Whitney test. $a$ : mean \pm standard deviation; n: number of specimens.

observed that unfed Panstrongylus megistus females which remained together with males after the last ecdysis were more fecund, laying more eggs than unfed unmated females. In our study, we observed the same response in T. brasiliensis. Mated unfed females produced on average five times more eggs than unmated unfed females.

Our study also made an unexpected observation regarding mating in fed females. From the first studies of the triatomine reproduction, it has been stated that only one mating is enough for the triatomine female to maintain fertile eggs for her entire life-span (Neiva 1910, Lima et al. 1987a, Pires et al. 2004). However, we observed a much higher fertility rate and fecundity in multiple mated fed females compared to single mated fed females. This finding suggests that a female is not able to maintain adequate amounts of spermatozoids in her spermathecae when mated only once. This inability could result from the lone male's failure to deliver to the female enough spermatozoids or other male secretions in a single copulation, or that the female empties much of the contents of her spermathecae as a single egg passes through the genital tract to the substrate. In the latter case, a female would require more than one copulation to continue to produce fertilized eggs. Other factors may also be involved, such as the reproductive competence of a single male or the duration of copulation, a factor in successful inseminations with Lygaeidae bugs, cousins to the triatomine (Micholitsche et al. 2000, Wang et al. 2008). Our finding warrants a further investigation of reproductive physiology of $T$. brasiliensis especially the organs and processes associated with copulation, insemination and egg laying.

Regarding the time spent as an adult until the first oviposition occurred, we observed that regularly fed unmated females took almost twice as long to initiate ovipositioning than regularly fed multiple or single mated females. This preoviposition period appears to be related more to mating than to feeding as the initiation of egg laying in unmated insects lags behind mated insects whether fed or not. Due to the nature of this study, insects were not sacrificed to determine the progression of egg maturation in the ovaries. Therefore, it is possi- ble that the unmated animals retained their unfertilized eggs whereas the mated animals laid their fertilized eggs as they were ovulated. This observation has been made for Rhodnius prolixus in which the fed unmated female will begin egg laying several days after the fed mated female (Chiang 1998) although egg production continues at the same rate in each during this time (Davey et al. 1986). Asin and Crocco (1992) also observed that in Triatoma infestans, mating stimulated ovipositioning, since mated females started to lay eggs from the 13th day onwards after imaginal ecdysis, whereas unmated females did not lay eggs during the first gonadotrophic cycle. These authors also suggest that unmated females could keep their eggs in the genital tract, because a big number of ovulated eggs were found in them compared to the mated ones.

Brasileiro (1982) observed that unmated females of $T$. brasiliensis had a higher longevity than that of multiple mated females. In our study, we did not observe any significant difference in life-span between the mated and unmated animals whether they were fed or not. We did observe that feeding greatly increased the life-span such that regularly fed insects lived approximately twice as long as unfed insects.

Compared to the life-spans reported for other fed triatomines, the life-span we observed for $T$. brasiliensis females (90-120 days) is similar to Triatoma gerstaeckeri and Triatoma sanguisuaga (Wood 1964) but considerably shorter compared to adult life-spans of over 200 days recently reported for some triatomines (Martinez-Ibarra \& Katthain-Duchateau 1999, Cabello \& Lizano 2001, Wolff et al. 2004). Conversely, the life-spans we observed for unfed animals are similar to those reported for unfed Triatoma lecticularia (Jurberg \& Costa 1989) and unfed $T$. brasiliensis (Costa \& Perondini 1973). Perhaps, the food source used for our colony may be adequate for maximal fecundity, but may lack some essential substances required for improving longevity. Guarneri et al. (2000) observed that T. brasiliensis fed on pigeons had a shorter life than those fed on mice, although there was no difference in fecundity between the blood sources.

Studies on all the biological aspects of secondary triatomine species are important as they may contribute to the design of control programs. The Brazilian Northeast is the endemic region of Chagas disease with more problems, because it is the dispersion center of T. brasiliensis, actually considered the most difficult triatomine to control (Dias 2007). In these regions, this species is always found in large densities in its natural ecotope, the Caatinga, where the ecological characteristics facilitate its development. Deforestation together with other human interferences in this environment has caused the displacement of this species to peridomiciles and from these to intradomiciles. In our study, T. brasiliensis females displayed good reproductive performance, even in starvation or absence of multiple copulations providing a physiological basis for its reproductive success in the wild. These results indicate the need for constant vigilance in maintaining an effective control program for this species. 


\section{REFERENCES}

Asin S, Crocco de Ayerbe L 1992. Influence of mating on ovarian follicle development in Triatoma infestans (Klug, 1834). Mem Inst Oswaldo Cruz 87: 369-374.

Brasileiro VLF 1982. Fecundidade e fertilidade da fêmea de Triatoma brasiliensis (Hemiptera: Reduviidae). I. Influencia da cópula e da nutrição. Rev Bras Biol 42: 1-13.

Cabello DR, Lizano E 2001. Biology of Triatoma flavida Neiva, 1911 (Hemiptera: Reduviidae) under laboratory conditions. Mem Inst Oswaldo Cruz 96: 1-3.

Chiang RG 1998. Partial localization of a brain factor inhibiting egg production in the blood-feeding insect, Rhodnius prolixus. Arch Insec Biochem Physiol 39: 126-131.

Costa MJ, Perondini ALP 1973. Resistência do Triatoma brasiliensis ao jejum. Rev Saude Publica 7: 207-217.

Davey KG 1974. Symposium of reproduction of artropods of medical and veterinary importance. IV. Reproduction in the females of some hematophagous insects. J Med Entomol 11: 40-45.

Davey KG, Maimets I-K, Ruegg RP 1986. The relationship between crop size and egg production in Rhodnius prolixus. Can J Zool 64: 2654-2657.

Davey KG, Singleton DM 1989. Activation of egg production and the corpus allatum without feeding in the adult female of the insect Rhodnius prolixus. Inv Reprod Dev 16: 131-134.

Dias JCP 1995. Prioridades de pesquisa no controle da doença de Chagas. Rev Soc Bras Med Trop 28: 23-26.

Dias JCP 2007. Southern Cone Initiative for the elimination of domestic populations of Triatoma infestans and the interruption of transfusional Chagas disease. Historical aspects, present situation and perspectives. Mem Inst Oswaldo Cruz 102: 11-18.

Espínola HN 1966. Nota sobre as diferenças sexuais em formas imaturas de triatomíneos (Hemiptera: Reduviidae). Rev Bras Biol 26: 263-267.

Garcia ES, Azambuja P 1985. Protein diet initiates oogenesis in Rhodnius prolixus. Brazilian J Med Biol Res 18: 195-199.

Guarneri AA, Pereira MH, Diotaiuti L 2000. Influence of the blood meal source on the development of Triatoma infestans, Triatoma brasiliensis, Triatoma sordida and Triatoma pseudomaculata (Heteroptera: Reduviidae). J Med Entomol 37: 373-379.

Jurberg J, Costa JM 1989. The resistance of fasting and nutritional aspects of Triatoma lecticularia (Stal, 1859) (Hemiptera: Reduviidae: Triatominae). Mem Inst Oswaldo Cruz 84: 393-399.
Lima JEPG, Azambuja P, Garcia ES 1990. Comparative studies on the growth and reproductive performances of $R$. prolixus reared on different blood sources. Mem Inst Oswaldo Cruz 85: 299-304.

Lima MM, Jurberg P, Almeida JR 1987a. Behavior of triatomines (Hemiptera: Reduviidae) vectores of Chagas disease. III. Influence of the number of matings on the fecundity and fertility of Panstrongylus megistus (Burm., 1835) in the laboratory. Mem Inst Oswaldo Cruz 82: 37-41.

Lima MM, Jurberg P, Almeida JR 1987b. Behavior of triatomines (Hemiptera: Reduviidae) vectors of Chagas disease. IV. Fecundity, fertility and longevity of Panstrongylus megistus (Burm., $1835)$ pairs and virgin females starved under laboratory conditions. Mem Inst Oswaldo Cruz 82: 501-509.

Martinez-Ibarra JA, Katthain-Duchateau G 1999. Biology of Triatoma pallidipennis Stal 1945 (Hemiptera: Reduviidae: Triatominae) under laboratory conditions. Mem Inst Oswaldo Cruz 94: 837-839.

Micholitsch T, Krugel P, Pass G 2000. Insemination and fertilization in the seed bug Lygaeus simulans (Heteroptera: Lygaeidae). Eur J Ent 97: 13-18.

Neiva A 1910. Informações sobre a biologia de Conorhinus megistus (Burm., 1835). Mem Inst Oswaldo Cruz 2: 206-212.

Pires HH, Lorenzo MG, Lazzari CR, Diotaiuti L, Manrique G 2004. The sexual behaviour of Panstrongylus megistus (Hemiptera: Reduviidae): an experimental study. Mem Inst Oswaldo Cruz 99: 295-300.

Valle D, Gomes JEPL, Goldenberg S, Garcia E 1987. Rhodnius prolixus vitellogenesis: Dependence upon the blood source. $J$ Insect Physiol 4: 249-254.

Vitta ACR, Lorenzo MG 2009. Copulation and mate guarding behavior in Triatoma brasiliensis. J Med Entomol 46: 789-795.

Wang Q, Yang L, Hedderley D 2008. Function of prolonged copulation in Nysius huttoni white (Heteroptera: Lygaeidae) under male-baised sex ratio and high population density. J Insect Behavior 21: 89-99.

Wigglesworth VB 1959. The control of growth and form: a study of the epidermal cell in an insect, Cornell University Press, Ithaca, 140 pp.

Wigglesworth VB 1972. The principles of insect physiology, 7th ed., Chapman and Hall, London. 827 pp.

Wolff M, Cuartas E, Velasquez C, Jarmillo N 2004. Development cycle of Panstrongylus rufotuberculatus (Hemiptera: Reduviidae) under laboratory conditions. Ent Soc Am 41: 1010-1014.

Wood SF 1964. The laboratory culture of Triatoma (Hemiptera: Reduviidae). Bull World Health Org 31: 579-581. 